\title{
ESTRATÉGIAS DE MARKETING EM CANAIS ELETRÔNICOS DE ATENDIMENTO BANCÁRIOS
}

\author{
Simone Lopes Maciel ${ }^{1}$ \\ Jessica Gutierrez Almendros ${ }^{2}$ \\ Matheus Henrique Porto do Prado ${ }^{3}$ \\ Diogo Rosa da Silva ${ }^{4}$ \\ Rogerio Romano ${ }^{5}$ \\ José Dirnece Paes Tavares ${ }^{6}$
}

Resumo: O serviço de atendimento bancário através do celular pode ser feito a qualquer hora, em qualquer lugar, tudo na palma da mão, bom para satisfazer as necessidades dos usuários e minimizar o custo da empresa. Esse trabalho tem como objetivo comparar as estratégias de atendimento utilizadas pelos bancos via dispositivos móbile. Os métodos utilizados são de pesquisa qualitativa, bibliográficas e em internet. Apresenta uma análise dos serviços que o canal de atendimento de bancos denominados "Banco A e Banco $B$ " oferece, objetivando identificar oportunidades de melhorias no Móbile da empresa A.O trabalho identifica quais são os serviços bancários mais utilizados pelos usuários, para que assim possam ser implantados no sistema do banco A objeto da pesquisa, e demonstra o que precisa ser feito para alcançar o nível de atendimento feito pelos concorrentes.

Palavras-chave: Marketing; Serviços; Atendimento Eletrônico; Aplicativo.

\footnotetext{
1 Administração/Anhanguera de Jacareí SP, Brasil. E-mail: dirluci@uol.com.br.

2 Administração/Anhanguera de Jacareí SP, Brasil. E-mail: jessicagalmendros@hotmail.com.

3 Administração/Anhanguera de Jacareí SP, Brasil. E-mail: matheusprado@yahoo.com.br.

${ }^{4}$ Administração/Anhanguera de Jacareí SP, Brasil. E-mail: diogo.rosa@anhanguera.com.

${ }^{5}$ Administração/Anhanguera de Jacareí SP, Brasil. E-mail: rogerio.romano@anhanguera.com.

${ }^{6}$ Administração/Anhanguera de Jacareí SP, Brasil. E-mail: jose.dirnece@anhanguera.com.
} 